\title{
Anthropometric, metabolic, psychosocial and dietary factors associated with dropout in overweight and obese postmenopausal women engaged in a 6-month weight loss programme: a MONET study
}

\author{
Virginie Messier ${ }^{1,2} * \dagger$, Jessy Hayek ${ }^{3} \dagger$, Antony D. Karelis ${ }^{4}$, Lyne Messier ${ }^{1}$, Éric Doucet ${ }^{5}$, \\ Denis Prud'homme ${ }^{5}$, Rémi Rabasa-Lhoret ${ }^{1,2,6,7}$ and Irene Strychar ${ }^{1,6,7}$ \\ ${ }^{1}$ Department of Nutrition, Université de Montréal, Montreal, QC, Canada \\ ${ }^{2}$ Institut de Recherches Cliniques de Montréal (IRCM), Montreal, QC, Canada \\ ${ }^{3}$ School of Dietetics and Human Nutrition, McGill University, Montreal, QC, Canada \\ ${ }^{4}$ Department of Kinanthropology, Université du Québec à Montréal, Montreal, QC, Canada \\ ${ }^{5}$ Faculty of Health Sciences, School of Human Kinetics, University of Ottawa, Ottawa, ON, Canada \\ ${ }^{6}$ Research Center of the Centre Hospitalier de l'Université de Montréal (CRCHUM), Montreal, QC, Canada \\ ${ }^{7}$ Montreal Diabetes Research Center, Montreal, QC, Canada \\ (Received 8 July 2009 - Revised 10 September 2009 - Accepted 21 October 2009 - First published online 24 November 2009)
}

\begin{abstract}
The objective of the present study was to examine anthropometric, metabolic, psychosocial and dietary factors associated with dropout in a 6-month weight loss intervention aimed at reducing body weight by $10 \%$. The study sample included 137 sedentary, overweight and obese postmenopausal women, participating in a weight loss intervention that consisted of either energy restriction (ER) or ER with resistance training $(E R+R T)$. Anthropometric (BMI, percent lean body mass, percent fat mass, visceral adipose tissue and waist circumference), metabolic (total energy expenditure, RMR, insulin sensitivity and fasting plasma levels of leptin and ghrelin), psychosocial (body esteem, self-esteem, stress, dietary restraint, disinhibition, hunger, quality of life, self-efficacy, perceived benefits for controlling weight and perceived risk) and dietary (3-d food record) variables were measured. Thirty subjects out of 137 dropped out of the weight loss programme (22\%), with no significant differences in dropout rates between those in the ER and the ER + RT groups. Overall, amount of weight loss was significantly lower in dropouts than in completers ( -1.7 (SD 3.5) v. -5.6 (SD 4.3) kg, $P<0.05$ ); weekly weight loss during the first 4 weeks was also significantly lower. Dropouts consumed fewer fruit servings than completers (1.7 (SD 1.1) v. 2.7 (SD 1.53), $P<0.05$ ) and had higher insulin sensitivity levels (12.6 (SD 3.8$) v .11 .1$ (SD $2.8) \mathrm{mg}$ glucose/min per $\mathrm{kg}$ fat-free mass, $P<0.05$ ). The present results suggest that the rate of weight loss during the first weeks of an intervention plays an important role in the completion of the programme. Thus, participants with low rates of initial weight loss should be monitored intensely to undertake corrective measures to increase the likelihood of completion.
\end{abstract}

Dropouts: Weight loss intervention: Diet: Metabolism

Independently of the type of obesity treatment, adherence to a weight loss programme is unavoidable for its success ${ }^{(1-6)}$. Dropout is an important barrier to overcome in order to maximise the benefits of obesity treatments. In a systematic review and meta-analysis of eighty studies with 26455 subjects enrolled in randomised weight loss clinical trials ${ }^{(2)}$, the overall dropout rate was $29 \%$ at year 1 and $31 \%$ at the end of the studies duration (range from 1 to 5 years). Dropout rates have also been reported to vary between 8 and $67 \%$ in commercial and self-help weight loss programmes ${ }^{(5)}$, between 40 and $82 \%$ in clinic-based programmes ${ }^{(7-10)}$, and between 22 and $51 \%$ in behavioural treatment programmes ${ }^{(11-14)}$. The type of dietary intervention may also affect dropout rates, but results are contradictory; lower carbohydrate diets have been found to be associated with both higher ${ }^{(1)}$ and lower dropout rates ${ }^{(3,6)}$. The addition of a physical activity component to a weight loss programme tended to reduce dropout $^{(15)}$, but results are controversial ${ }^{(5)}$, possibly depending also on the type of exercise. Comparison between studies is difficult because of differences in the type of intervention, the study duration and the sample composition.

Numerous factors, other than type of weight loss intervention, have also been reported to be associated with dropout rates ${ }^{(6,7,9,12,14,16-25)}$. Psychosocial factors associated with dropout include lower self-efficacy ${ }^{(19)}$ and self-esteem ${ }^{(14)}$. A greater weight loss expectation ${ }^{(7,21)}$ and a slower rate of weight loss during the programme ${ }^{(11,22)}$ were also found to be positively associated with dropout, while the number of previous weight loss attempts was found to be both positively $^{(6,14)}$ and negatively ${ }^{(25)}$ associated. For anthropometric

Abbreviations: BW, body weight; ER, energy restriction; RT, resistance training.

* Corresponding author: Virginie Messier, fax +1 514987 5670, email virginie.messier@ircm.qc.ca

$\dagger$ Equal authorship. 
factors, percent body fat has been shown to be positively associated $^{(14)}$, while, in some studies, BMI was positively associated with dropout ${ }^{(14,15,17,19)}$ but not in others ${ }^{(9,20)}$. Finally, the relationship between metabolic factors and dropout has received little attention ${ }^{(16,24)}$.

A major limitation in this area of research is that most studies examining the profiles of dropout considered selectively either one of anthropometric, metabolic or psychosocial characteristics. Studying multiple factors, in the same study population, associated with dropout may help us better understand attrition rates in weight loss programmes in specific populations. Therefore, the purpose of the present study was to determine the anthropometric, metabolic, psychosocial and dietary factors related to dropout among overweight and obese postmenopausal women participating in a weight loss intervention, which consisted of a energy restriction (ER) programme with and without resistance training (RT).

\section{Methods}

The Montreal Ottawa New Emerging Team weight loss intervention was designed to reduce body weight (BW) by $10 \%$ and consisted of a 6-month randomised ER with or without RT. The present study was conducted according to the guidelines laid down in the Declaration of Helsinki, and all procedures involving human subjects/patients were approved by the Université de Montréal, Comité d'éthique de la Faculté de Médecine. Written informed consent was obtained from all subjects/patients. Data were collected from 2003 (initiation of recruitment) to 2006 (end of the intervention) on one site: Département de nutrition, Université de Montréal.

By design, there were twice as many women randomised in the ER group compared to the ER + RT group, as women who completed the 6-month ER weight loss intervention were asked to participate in a 12-month follow-up with or without RT. The present manuscript reports dropout results for the initial 6-month weight loss period.

The present study included 137 sedentary, overweight and obese postmenopausal women, recruited by newspaper advertisements. Women were eligible to participate if they met the following criteria: (1) $\mathrm{BMI} \geq 27 \mathrm{~kg} / \mathrm{m}^{2}$; (2) cessation of menstruation for more than 1 year and a follicle-stimulating hormone level $\geq 30 \mathrm{U} / 1$; (3) non-smokers; (4) low to moderate alcohol consumption $(<2$ drinks/d); (5) free of known inflammatory disease; (6) no use of hormone replacement therapy; (7) sedentary (less than $2 \mathrm{~h}$ per week of structured exercise). On physical examination or biological testing, all participants had no history or evidence of: (1) diabetes (fasting glucose $>7.1 \mathrm{mmol} / \mathrm{l}$ or 2 -h plasma glucose of $>11.1 \mathrm{mmol} / \mathrm{l}$ after a 75-g oral glucose tolerance test); (2) untreated thyroid or pituitary disease; (3) chronic liver or renal disease; (4) asthma requiring therapy with steroids; (5) CVD, peripheral vascular disease or stroke; (6) dyslipidaemia or hypertension requiring immediate medical intervention (total cholesterol $>8 \mathrm{mmol} / \mathrm{l}$, systolic blood pressure $>160 \mathrm{mmHg}$ or diastolic blood pressure $>100 \mathrm{mmHg}$ ); (7) history of alcohol or drug abuse; (8) use of medications that could affect cardiovascular function and/or metabolism; (9) BW fluctuation $\pm 2 \mathrm{~kg}$ in the last 3 months; (10) known history of inflammatory disease as well as cancer; (11) orthopaedic limitations.
Before beginning the intervention, women were invited to the Metabolic Unit at the Université de Montréal to assess anthropometric, metabolic, psychosocial and dietary profiles (testing was completed over a 1-month period). In addition, all testing was preceded by a 4-week weight stabilisation period; weight stability, within $\pm 2 \mathrm{~kg}$, was verified by a weekly weighing at our research unit. The weight stabilisation period was planned to reduce the acute effects of ER on outcome measures $^{(26)}$.

\section{Energy restriction intervention}

The 6-month weight loss programme was medically supervised with the goal of reducing $\mathrm{BW}$ by $10 \%$. To determine the level of ER, 2092-3347.2 kJ (500-800 kcal) ${ }^{(27)}$ were subtracted from individuals' energy requirements (baseline RMR, determined by indirect calorimetry, multiplied by a sedentary physical activity factor of $\left.1 \cdot 4^{(28)}\right)$. Diet prescriptions ranged from 4602.4 to $7531.2 \mathrm{~kJ} / \mathrm{d}$ (1100 to $1800 \mathrm{kcal} / \mathrm{d})$. Macronutrient composition of the diets was standardised: 55, 30 and $15 \%$ of energy intake, respectively, from carbohydrates, fat and proteins. Each subject met with the study dietitian to receive the diet prescription and was invited bimonthly for nutrition classes, $1-1.5 \mathrm{~h}$ in duration. Themes discussed during the group sessions included: food groups and their energy/nutrient content as well as portion sizes; self-evaluation of dietary intake and macronutrient distribution; dietary fats and portion size; fibre and ways to meet an intake of $25 \mathrm{~g} / \mathrm{d}$; protein and its effect on satiety; desserts (necessity and nutrient and energy values); identification of physiological and emotional cues to hunger; stage of readiness to lose weight; fad diets and weight loss products. All subjects in the ER group were instructed to maintain their habitual physical activities during the weight loss protocol. During the weight loss intervention, subjects were asked to come to the metabolic unit once per week in order to be weighed.

\section{Resistance training intervention}

The 6-month RT programme consisted of four progressive phases and was performed weekly on three non-consecutive days (phase 1: introduction to training (3 weeks, fifteen repetitions, two to three sets per exercise, 90-120 s between sets); phase 2 (5 weeks, twelve repetitions, two to three sets per exercise, $90 \mathrm{~s}$ between sets); phase 3 (9 weeks, eight to ten repetitions, two to four sets per exercise, $120-180 \mathrm{~s}$ between sets); phase 4 ( 8 weeks, ten to twelve repetitions, three to four sets per exercise, 60-90 s between sets)). Each training session included a warm-up of low-intensity walking on a treadmill for $10 \mathrm{~min}$. The RT programme consisted of the following exercises: (1) leg press; (2) chest press; (3) lateral pull downs; (4) shoulder press; (5) arm curls; (6) triceps extensions. These exercises provide a total body RT programme for all the major muscle groups of the body. Each exercise session was individually monitored by qualified personal trainers.

\section{Anthropometric, metabolic, psychosocial and dietary assessments}

Anthropometric assessment included BW measurement using an electronic scale (Balance Industrielles, Montreal, Canada), 
and standing height measurement using a wall stadiometer (Perspective Enterprises, Portage, MI, USA), as previously described $^{(29-32)}$. Thereafter, BMI (BW $(\mathrm{kg}) /$ height $\left.^{2}(\mathrm{~m})\right)$ was calculated. BMI at 25 years was calculated using self-report weight at 25 years and current height. The methods for body composition, visceral adipose tissue and waist circumference assessment were determined as previously described ${ }^{(29-32)}$.

Metabolic assessments included measures of total energy expenditure, RMR and RQ, as previously described ${ }^{(30,32)}$. The hyperinsulinaemic-euglycaemic clamp technique was used to measure insulin sensitivity. Insulin infusion rate was maintained at $75 \mathrm{mU} / \mathrm{m}^{2}$ for $180 \mathrm{~min}$ : during the last $30 \mathrm{~min}$ of the clamp (steady state), glucose disposal was calculated as the mean rate of glucose infusion measured, expressed as $\mathrm{mg} / \mathrm{min}$ per $\mathrm{kg}$ fat-free mass ${ }^{(30)}$. Fasting plasma concentrations of leptin and ghrelin were measured in duplicate with a commercial RIA procedure ${ }^{(31)}$.

Psychosocial assessment was completed using a validated self-administered questionnaire, as previously described ${ }^{(33)}$. Body esteem was assessed using Mendelson et al.'s bodyesteem scale $^{(34)}$ (appearance, attribution and weight subscales); self-esteem was assessed using Rosenberg's scale ${ }^{(35)}$; perceived stress was assessed using Cohen et al.'s ${ }^{(36)}$ perceived stress scale; dietary restraint, disinhibition and hunger were assessed using the Stunkard \& Messick's ${ }^{(37)}$ three-factor eating questionnaire; quality of life was measured using the Medical Outcomes Study General Health Survey ${ }^{(38,39)}$ (health perceptions, mental health, role functioning, social functioning, physical functioning and pain subscales). Self-efficacy for controlling weight was assessed with questions developed for the present study according to social cognitive theory ${ }^{(34)}$. Perceived benefits for controlling weight and perceived risk for heart disease and diabetes were developed for the present study according to the Health Belief Model $^{(34)}$. Internal consistency reliability for measures with more than one item was assessed using Cronbach's $\alpha$-coefficients ${ }^{(34)}$ and ranged from 0.62 to 0.91 .

Dietary assessment included percentage of energy from carbohydrates, protein and fat (total, saturated, monounsaturated, polyunsaturated and trans), based on a 3-d food record as previously described ${ }^{(32)}$. Analyses were conducted with the Food Processor SQL program (ESHA Inc.) using the 2001 Canadian Nutrient Data File. Number of fruit and vegetable servings was calculated from the food records.

\section{Statistical analysis}

Individuals were classified as dropouts if they withdrew during the intervention or did not come to the research unit for body composition assessment at the end of the 6-month intervention, since changes in body composition were the primary outcomes of the Montreal Ottawa New Emerging Team study. Thirty-three individuals were screened and withdrew before randomisation because there were insufficient data on these individuals to be included in the present study. To determine differences between those who completed the programme and those who dropped out, independent $t$ tests were used. A repeated-measures ANOVA was used to detect changes in BW during the first 4 weeks of the intervention within each group and between the groups (time $\times$ group interaction). When a significant time $\times$ group interaction was found, we performed $t$ test analyses to detect the time effect in each group. The SPSS program was used for analysis (SPSS, Chicago, IL, USA). Values are expressed as the means and standard deviations.

\section{Results}

During the 6-month weight loss intervention, thirty subjects out of 137 dropped out of the weight loss programme (22\%). Women's reasons for dropouts were described as follows ${ }^{(31)}$ : health problems not related to training ( $n 5)$; minor injury related to RT ( $n$ 3); refusal of 6-month post-testing ( $n$ 3); conflicting time schedules ( $n$ 4); personal/family problems ( $n$ 2); weight loss too slow ( $n 3$ ); travel distance to the research unit ( $n 3)$; unspecified reasons ( $n$ 7). There was no difference in the dropout rate between the ER $+\mathrm{RT}$ group and the ER group ( $25 \%$ v. $20 \%, P=\mathrm{NS})$. Therefore, to compare the anthropometric, metabolic, psychosocial as well as dietary factors of completers and dropouts, we pooled the dropouts and completers of the two types of interventions.

Dropout occurred at various times throughout the intervention: eight had dropped out by the end of the first month, nine by the end of the second month, two by 3 months and eleven after 3 months. Overall, amount of weight loss (final weight baseline weight) was significantly lower in dropouts than in completers $(-1.7$ (SD 3.5) v. $-5.6(\mathrm{SD} 4.3) \mathrm{kg}, P<0.05)$. Furthermore, weekly weight loss during the first 4 weeks was also significantly lower among dropouts (Table 1), but not during subsequent weeks (data not shown). Dropouts began to

Table 1. Anthropometric and metabolic characteristics of completers and dropouts

(Mean values and standard deviations)

\begin{tabular}{|c|c|c|c|c|}
\hline \multirow[b]{2}{*}{ Variables } & \multicolumn{2}{|c|}{ Completers (n 107) } & \multicolumn{2}{|c|}{ Dropouts (n 30) } \\
\hline & Mean & SD & Mean & SD \\
\hline Age (years) & $58 \cdot 0$ & $4 \cdot 9$ & $56 \cdot 6$ & $4 \cdot 6$ \\
\hline $\mathrm{BW}(\mathrm{kg})$ & $84 \cdot 4$ & $14 \cdot 5$ & $82 \cdot 3$ & 9.9 \\
\hline \multicolumn{5}{|c|}{ Change in BW from baseline (\%) } \\
\hline Week 1 & $-0.90 \dagger$ & 1.64 & $0 \cdot 49^{*}$ & $2 \cdot 77$ \\
\hline Week 2 & $-1.54 \dagger$ & $1 \cdot 70$ & $-0 \cdot 26^{\star}$ & 1.98 \\
\hline Week 3 & $-2 \cdot 10 \dagger$ & 1.79 & $-0.88^{*} \dagger$ & 1.89 \\
\hline Week 4 & $-2 \cdot 68 \dagger$ & 1.79 & $-1 \cdot 48^{\star} \dagger$ & $2 \cdot 05$ \\
\hline \multicolumn{5}{|l|}{ BMI $\left(\mathrm{kg} / \mathrm{m}^{2}\right)$} \\
\hline Current & $32 \cdot 6$ & $4 \cdot 7$ & $32 \cdot 8$ & $4 \cdot 2$ \\
\hline At 25 years & $22 \cdot 5$ & $3 \cdot 0$ & $21 \cdot 9$ & $2 \cdot 1$ \\
\hline LBM (\%) & $51 \cdot 5$ & $4 \cdot 6$ & $49 \cdot 9$ & $4 \cdot 4$ \\
\hline $\mathrm{FM}(\%)$ & $45 \cdot 5$ & $4 \cdot 7$ & $47 \cdot 1$ & 4.5 \\
\hline $\operatorname{VAT}\left(\mathrm{cm}^{2}\right)$ & $185 \cdot 2$ & $54 \cdot 5$ & $188 \cdot 2$ & $58 \cdot 9$ \\
\hline WC $(\mathrm{cm})$ & 103.5 & $11 \cdot 7$ & $103 \cdot 0$ & $9 \cdot 0$ \\
\hline TEE $(\mathrm{kJ} / \mathrm{d})$ & 10465 & 1609 & 10046 & 1651 \\
\hline $\operatorname{RMR}(\mathrm{kJ} / \mathrm{d})$ & 5524 & 802 & 5460 & 679 \\
\hline $\mathrm{RMR} / \mathrm{kg}$ of $\mathrm{BW}$ & $66 \cdot 6$ & $6 \cdot 8$ & $67 \cdot 2$ & $7 \cdot 7$ \\
\hline $\mathrm{RQ}$ & 0.9 & 0.1 & 0.9 & $0 \cdot 1$ \\
\hline IS (mg/min per kg FFM) & $11 \cdot 1$ & $2 \cdot 8$ & $12 \cdot 6^{\star}$ & $3 \cdot 8$ \\
\hline Leptin (ng/ml) $\ddagger$ & $26 \cdot 8$ & $9 \cdot 2$ & $32 \cdot 0$ & $9 \cdot 9$ \\
\hline Ghrelin (pg/ml)§ & $1107 \cdot 6$ & 345.5 & $1276 \cdot 4$ & $544 \cdot 0$ \\
\hline
\end{tabular}

BW, body weight; LBM, lean body mass; FM, fat mass; VAT, visceral adipose tissue; WC, waist circumfrance; TEE, total energy expenditure; IS, insulin sensitivity; FFM, fat FM.

*Mean value was significantly different from that of the completers $(P<0.05)$. †Mean weight loss from baseline was significant, within the group $(P<0.05)$. ¥Data available for fifty completers and seventeen dropouts.

$\S$ Data available for forty-two completers and fifteen dropouts. 
lose weight only at week 3 , whereas completers had lost weight from week 1.

The anthropometric and metabolic characteristics of completers and dropouts are reported in Table 1. We observed that insulin sensitivity levels were significantly higher in dropouts compared to completers $(12.6$ (SD 3.8) v. 11.1 (SD 2.8) $\mathrm{mg}$ glucose/min per $\mathrm{kg}$ fat-free mass, $P<0.05)$; no other significant differences were found.

Psychosocial and dietary characteristics of completers and dropouts are presented in Tables 2 and 3, respectively. No differences were noted for any psychosocial nor dietary variables except that the number of portions of fruit servings, calculated according to Canada's Food Guide, was significantly lower in dropouts than in completers (1.7 (SD 1.1) v. 2.7 (SD 1.5), $P<0.05)$.

\section{Discussion}

The purpose of the present study was to determine the anthropometric, metabolic, psychosocial and dietary factors related to dropout in overweight and obese postmenopausal women engaged in a 6-month weight loss intervention. We found that the addition of a RT component to a ER weight loss programme did not affect dropout rates in a university-based research setting. We did, however, observe significant differences for the rate of weight loss, for insulin sensitivity levels and for fruit servings between completers and dropouts.

When women were asked their reasons for dropping out of the programme, most answers were related to personal (i.e. time constraints and family problems) and organisational issues (i.e. location of the research unit and travel time to reach it); yet, unsatisfactory weight loss may be an important

Table 2. Psychosocial characteristics of completers and dropouts* (Mean values and standard deviations)

\begin{tabular}{|c|c|c|c|c|}
\hline \multirow[b]{2}{*}{ Variables } & \multicolumn{2}{|c|}{ Completers ( $n$ 107) } & \multicolumn{2}{|c|}{ Dropouts (n 30) } \\
\hline & Mean & SD & Mean & SD \\
\hline Self-efficacy (1-4) & $2 \cdot 7$ & 0.5 & $2 \cdot 8$ & 0.5 \\
\hline Perceived benefits $(1-4)$ & $3 \cdot 6$ & 0.4 & 3.8 & 0.3 \\
\hline \multicolumn{5}{|l|}{ Perceived risks for } \\
\hline Heart disease (1-4) & 2.9 & 0.9 & 2.9 & 0.8 \\
\hline Diabetes (1-4) & $2 \cdot 7$ & 0.9 & 3.0 & $1 \cdot 0$ \\
\hline Self-esteem (1-4) & $1 \cdot 8$ & 0.5 & 1.9 & 0.5 \\
\hline Stress $(0-56)$ & $18 \cdot 6$ & 8.5 & $20 \cdot 2$ & $6 \cdot 6$ \\
\hline Body esteem (0-4) & 1.4 & 0.5 & 1.5 & 0.5 \\
\hline Appearance & 1.5 & 0.6 & $1 \cdot 6$ & 0.6 \\
\hline Weight & 1.0 & 0.6 & 1.0 & 0.6 \\
\hline Attribution & 1.9 & 0.6 & $2 \cdot 0$ & 0.5 \\
\hline \multicolumn{5}{|c|}{ Three-factor eating questionnaire } \\
\hline Restraint $(0-21)$ & $11 \cdot 1$ & 3.8 & $11 \cdot 3$ & $3 \cdot 7$ \\
\hline Disinhibition $(0-16)$ & $8 \cdot 2$ & 3.5 & $7 \cdot 9$ & 3.7 \\
\hline Hunger $(0-14)$ & $5 \cdot 4$ & $3 \cdot 1$ & $5 \cdot 1$ & $2 \cdot 7$ \\
\hline Quality of life $(0-100)$ & 78 & 13 & 81 & 17 \\
\hline Physical functioning & 80 & 25 & 84 & 23 \\
\hline Pain & 57 & 29 & 69 & 34 \\
\hline Social functioning & 96 & 12 & 95 & 11 \\
\hline Role functioning & 87 & 24 & 85 & 28 \\
\hline Mental health & 71 & 15 & 70 & 17 \\
\hline Health perceptions & 78 & 18 & 75 & 20 \\
\hline
\end{tabular}

*Higher scores indicate higher body esteem, lower self-esteem, greater stress, greater dietary restraint, greater disinhibition, greater hunger, greater quality of life, greater self-efficacy, greater perceived benefits and greater perceived risk.
Table 3. Dietary profile of completers and dropouts (Mean values and standard deviations)

\begin{tabular}{|c|c|c|c|c|}
\hline \multirow[b]{2}{*}{ Variables } & \multicolumn{2}{|c|}{ Completers $(n 75)$} & \multicolumn{2}{|c|}{ Dropouts $(n 14)$} \\
\hline & Mean & SD & Mean & SD \\
\hline Energy intake (kJ) & 8271.77 & 2079.45 & $7748 \cdot 77$ & $1506 \cdot 24$ \\
\hline Carbohydrates (\% energy) & $48 \cdot 3$ & 6.5 & $47 \cdot 2$ & 3.8 \\
\hline Protein (\% energy) & $16 \cdot 5$ & $3 \cdot 1$ & $17 \cdot 4$ & $3 \cdot 1$ \\
\hline Total fat (\% energy) & 31.7 & $5 \cdot 7$ & $32 \cdot 8$ & 4.9 \\
\hline SFA (\% energy) & $10 \cdot 4$ & $2 \cdot 7$ & $11 \cdot 0$ & $2 \cdot 6$ \\
\hline MUFA (\% energy) & $11 \cdot 0$ & $3 \cdot 1$ & $11 \cdot 4$ & $2 \cdot 3$ \\
\hline PUFA (\% energy) & $5 \cdot 1$ & $2 \cdot 0$ & $6 \cdot 1$ & 1.9 \\
\hline trans-fat (\% energy) & 0.2 & 0.3 & 0.2 & 0.3 \\
\hline Fruits (servings/d) & $2 \cdot 7$ & 1.5 & $1.7^{\star}$ & 1.1 \\
\hline Vegetables (servings/d) & 3.9 & $2 \cdot 2$ & 3.5 & 1.0 \\
\hline
\end{tabular}

* Mean values were significantly different from completers $(P<0.05)$.

consideration in explaining dropout. We noted that the weekly weight loss rate was significantly different between completers and dropouts. Accordingly, it has been shown that weight loss over the first 2 weeks of a weight management programme using meal replacements was a predictor of the continuation in the programme ${ }^{(24)}$. Moreover, Finley et al. ${ }^{(40)}$ observed that clients who dropped out of a commercial weight loss programme during the first 4 weeks lost about $1 \%$ of their initial BW compared with about $12 \%$ weight loss for clients who remained in the programme for at least 40 weeks. Furthermore, the Finley study showed that percent weight loss was directly associated with the amount of time an individual remained in the weight loss programme ${ }^{(40)}$. Thus, we believe that weight loss during the first weeks of a weight loss intervention should be given a particular attention in order to maximise the retention of the participants in the programme. An initial slow rate of weight loss may discourage participants and lower their motivation to continue their weight loss efforts. Possible reasons for this slower rate of weight loss could include difficulties in adhering to the diet prescription. A more in-depth understanding of the factors leading to slow rate of weight loss may help us to better assist individuals in their weight loss endeavours.

We observed that insulin sensitivity levels were significantly higher in dropouts compared to completers. Several studies have shown that high levels of insulin sensitivity might have a negative impact on weight loss ${ }^{(41,42)}$ or weight gain $^{(43)}$. Accordingly, Hoffman et al. ${ }^{(42)}$ observed a negative association between insulin sensitivity and weight loss in obese children, suggesting that insulin resistance may enhance weight loss during ER. In addition, Cornier et al. ${ }^{(41)}$ observed that a low-carbohydrate/high-fat diet induced a greater weight loss in insulin-resistant individuals than in insulin-sensitive individuals. Furthermore, Swinburn et al. ${ }^{(43)}$ examined the relationship between insulin sensitivity and weight gain in 192 non-diabetic Pima Indians. The present study showed that over 3.5 years, insulin-sensitive individuals gained more weight than insulin-resistant individuals ${ }^{(43)}$. Thus, in the present study, high levels of insulin sensitivity may have limited weight loss, one possible reason for explaining slow rate of weight loss found among our dropouts. However, it should be noted that although statistically significant differences in insulin sensitivity were obtained between groups, the small differences may not be clinically significant. 
We did not observe differences in the psychosocial profile between dropouts and completers, while other studies have shown that individuals who dropped out of a weight loss intervention were different from completers for several psychosocial variables ${ }^{(14,18,25)}$. For example, Teixeira et al. ${ }^{(14)}$ reported that non-completion of a lifestyle weight loss programme was associated with poorer quality of life as well as an unfavourable psychosocial health and body image. Furthermore, it has been reported that emotional disturbance ${ }^{(25)}$ and depression ${ }^{(18)}$ are also associated with dropout in a weight loss intervention. While no psychosocial factors in the present study were associated with dropout, we noted that among completers, the self-reported consumption of fresh fruits was significantly higher than in dropouts. The present results are similar to those of Inelmen et al. ${ }^{(22)}$ who reported that dropouts consumed less fruits than completers. Further research is needed to examine changes in dietary profiles during the intervention and their influence of rates of dropout. Finally, no difference in BMI was noted between completers and dropouts. The impact of BMI on dropout is controversial since some studies observed that BMI was positively associated with dropout $^{(12,14)}$, while others did not observed this association ${ }^{(9,20)}$.

The present study has some limitations. The present findings are limited to a cohort composed of non-diabetic sedentary overweight and obese postmenopausal women who participated in a university-based research weight loss programme. Therefore, future studies may want to examine dropout-related factors in different age groups across the lifespan and in groups with chronic illnesses. Moreover, we did not assess adherence to the diet throughout the intervention nor monitored appetite, which may have correlated with weight loss and dropout. Nevertheless, the present results are strengthened by the use of gold standard techniques and questionnaires to measure insulin sensitivity, the psychosocial and dietary profile in a relatively large sample size of wellcharacterised overweight and obese postmenopausal women.

In conclusion, the present results suggest that weight loss during the first weeks of a weight loss intervention is a crucial determinant of dropout in overweight and obese postmenopausal women. Moreover, the different weight loss pattern between completers and dropouts underscores the importance of monitoring and supporting subjects at the beginning of a weight loss programme.

\section{Acknowledgements}

The present study was supported by grants from the Canadian Institute of Health Research New and Emerging Teams in Obesity (Université de Montréal and University of Ottawa; Montreal Ottawa New Emerging Team project). V. M., A. K. and R. R.-L. were supported by the Fonds de la recherche en santé du Québec (FRSQ). É. D. is a recipient of a CIHR/ Merck-Frosst New Investigator Award, a Canadian Foundation for Innovation New Opportunities Award and an Early Research Award (Ontario). All the authors disclose no conflict of interest. The author's contribution is as follows: V. M. did collection of data, analysis of data and writing of the manuscript. J. H. did collection of data and writing of the manuscript. A. D. K. did analysis of data and provision of significant advice. L. M. did collection of data and provision of significant advice. D. P. did design of the experiment and provision of significant advice. É. D. did design of the experiment and provision of significant advice. R. R.-L. did design of the experiment and provision of significant advice. I. S. did design of the experiment, analysis of data and provision of significant advice.

\section{References}

1. Dansinger ML, Gleason JA, Griffith JL, et al. (2005) Comparison of the Atkins, Ornish, weight watchers, and zone diets for weight loss and heart disease risk reduction: a randomized trial. JAMA 293, 43-53.

2. Franz MJ, VanWormer JJ, Crain AL, et al. (2007) Weight-loss outcomes: a systematic review and meta-analysis of weight-loss clinical trials with a minimum 1-year follow-up. J Am Diet Assoc 107, 1755-1767.

3. Gardner CD, Kiazand A, Alhassan S, et al. (2007) Comparison of the Atkins, Zone, Ornish, and LEARN diets for change in weight and related risk factors among overweight premenopausal women: the A TO Z Weight Loss Study: a randomized trial. JAMA 297, 969-977.

4. Tsai AG \& Wadden TA (2005) Systematic review: an evaluation of major commercial weight loss programs in the United States. Ann Intern Med 142, 56-66.

5. Wu T, Gao X, Chen M, et al. (2009) Long-term effectiveness of diet-plus-exercise interventions vs. diet-only interventions for weight loss: a meta-analysis. Obes Rev 10, 313-323.

6. Yancy WS Jr, Olsen MK, Guyton JR, et al. (2004) A low-carbohydrate, ketogenic diet versus a low-fat diet to treat obesity and hyperlipidemia: a randomized, controlled trial. Ann Intern Med 140, 769-777.

7. DalleGrave R, Calugi S, Molinari E, et al. (2005) Weight loss expectations in obese patients and treatment attrition: an observational multicenter study. Obes Res 13, 1961-1969.

8. Grossi E, Dalle Grave R, Mannucci E, et al. (2006) Complexity of attrition in the treatment of obesity: clues from a structured telephone interview. Int J Obes (Lond) 30, 1132-1137.

9. Honas JJ, Early JL, Frederickson DD, et al. (2003) Predictors of attrition in a large clinic-based weight-loss program. Obes Res 11, 888-894.

10. Wadden TA, Foster GD, Letizia KA, et al. (1992) A multicenter evaluation of a proprietary weight reduction program for the treatment of marked obesity. Arch Intern Med 152, 961-966.

11. Andersson I \& Rossner S (1997) Weight development, drop-out pattern and changes in obesity-related risk factors after two years treatment of obese men. Int J Obes Relat Metab Disord 21, 211-216.

12. Clark MM, Guise BJ \& Niaura RS (1995) Obesity level and attrition: support for patient-treatment matching in obesity treatment. Obes Res 3, 63-64.

13. Lantz H, Peltonen M, Agren L, et al. (2003) A dietary and behavioural programme for the treatment of obesity. A 4-year clinical trial and a long-term posttreatment follow-up. J Intern Med 254, 272-279.

14. Teixeira PJ, Going SB, Houtkooper LB, et al. (2004) Pretreatment predictors of attrition and successful weight management in women. Int J Obes Relat Metab Disord 28, 1124-1133.

15. Neumark-Sztainer D, Kaufmann NA \& Berry EM (1995) Physical activity within a community-based weight control program: program evaluation and predictors of success. Public Health Rev 23, 237-251.

16. Bautista-Castano I, Molina-Cabrillana J, Montoya-Alonso JA, et al. (2004) Variables predictive of adherence to diet and physical activity recommendations in the treatment of obesity and overweight, in a group of Spanish subjects. Int J Obes Relat Metab Disord 28, 697-705. 
17. Carels RA, Cacciapaglia HM, Douglass OM, et al. (2003) The early identification of poor treatment outcome in a women's weight loss program. Eat Behav 4, 265-282.

18. Clark MM, Niaura R, King TK, et al. (1996) Depression, smoking, activity level, and health status: pretreatment predictors of attrition in obesity treatment. Addict Behav 21, 509-513.

19. Dennis KE, Tomoyasu N, McCrone SH, et al. (2001) Self-efficacy targeted treatments for weight loss in postmenopausal women. Sch Inq Nurs Pract 15, 259-276.

20. Ek A, Andersson I, Barkeling B, et al. (1996) Obesity treatment and attrition: no relationship to obesity level. Obes Res 4, 295-296.

21. Fowler JL, Follick MJ, Abrams DB, et al. (1985) Participant characteristics as predictors of attrition in worksite weight loss. Addict Behav 10, 445-448.

22. Inelmen EM, Toffanello ED, Enzi G, et al. (2005) Predictors of drop-out in overweight and obese outpatients. Int J Obes (Lond) 29, $122-128$.

23. Kaplan RM \& Atkins CJ (1987) Selective attrition causes overestimates of treatment effects in studies of weight loss. Addict Behav 12, 297-302.

24. Packianathan I, Sheikh M, Boniface D, et al. (2005) Predictors of programme adherence and weight loss in women in an obesity programme using meal replacements. Diabetes Obes Metab 7, 439-447.

25. Yass-Reed EM, Barry NJ \& Dacey CM (1993) Examination of pretreatment predictors of attrition in a VLCD and behavior therapy weight-loss program. Addict Behav 18, 431-435.

26. Weinsier RL, Nagy TR, Hunter GR, et al. (2000) Do adaptive changes in metabolic rate favor weight regain in weight-reduced individuals? An examination of the set-point theory. Am J Clin Nutr 72, 1088-1094.

27. Lau DC, Douketis JD, Morrison KM, et al. (2007) 2006 Canadian clinical practice guidelines on the management and prevention of obesity in adults and children. CMAJ 176, S1-13.

28. Tremblay A, Pelletier C, Doucet E, et al. (2004) Thermogenesis and weight loss in obese individuals: a primary association with organochlorine pollution. Int J Obes Relat Metab Disord 28, 936-939.

29. Brochu M, Malita MF, Messier V, et al. (2009) Resistance training does not contribute to improving the metabolic profile after a 6-month weight loss program in overweight and obese postmenopausal women. J Clin Endocrinol Metab 94, 3226-3233.

30. Messier V, Malita FM, Rabasa-Lhoret R, et al. (2008) Association of cardiorespiratory fitness with insulin sensitivity in overweight and obese postmenopausal women: a Montreal Ottawa New Emerging Team study. Metabolism 57, 1293-1298.

31. St-Pierre DH, Faraj M, Karelis AD, et al. (2006) Lifestyle behaviours and components of energy balance as independent predictors of ghrelin and adiponectin in young non-obese women. Diabetes Metab 32, 131-139.

32. Strychar I, Lavoie M-E, Messier L, et al. (2009) Anthropometric, metabolic, psychosocial, and dietary characteristics of overweight/obese postmenopausal women with a history of weight cycling: A MONET (Montreal Ottawa New Emerging Team) study. J Am Diet Assoc 109, 718-724.

33. Karelis AD, Fontaine J, Messier V, et al. (2008) Psychosocial correlates of cardiorespiratory fitness and muscle strength in overweight and obese post-menopausal women: a MONET study. J Sports Sci 26, 935-940.

34. Ghiselli EE, Campbell JP \& Zedeck S (1981) Measurement Theory for the Behavioral Sciences. San Francisco, CA: W.H. Freeman.

35. Rosenberg M (1965) Society and the Adolescent Self-image. Princeton, NJ: Princeton University Press.

36. Cohen S, Kamarck T \& Mermelstein R (1983) A global measure of perceived stress. J Health Soc Behav 24, 385-396.

37. Stunkard AJ \& Messick S (1985) The three-factor eating questionnaire to measure dietary restraint, disinhibition and hunger. J Psychosom Res 29, 71-83.

38. McDowell I \& Newell C (1996) Measuring Health: A Guide to Rating Scales and Questionnaires, 2nd ed. New York: Oxford University Press.

39. Stewart AL, Greenfield S, Hays RD, et al. (1989) Functional status and well-being of patients with chronic conditions. Results from the Medical Outcomes Study. JAMA 262, 907-913.

40. Finley CE, Barlow CE, Greenway FL, et al. (2007) Retention rates and weight loss in a commercial weight loss program. Int $J$ Obes (Lond) 31, 292-298.

41. Cornier MA, Donahoo WT, Pereira R, et al. (2005) Insulin sensitivity determines the effectiveness of dietary macronutrient composition on weight loss in obese women. Obes Res 13, 703-709.

42. Hoffman RP, Stumbo PJ, Janz KF, et al. (1995) Altered insulin resistance is associated with increased dietary weight loss in obese children. Horm Res 44, 17-22.

43. Swinburn BA, Nyomba BL, Saad MF, et al. (1991) Insulin resistance associated with lower rates of weight gain in Pima Indians. J Clin Invest 88, 168-173. 